\title{
A Complimentary Relationship: Psychotherapy and Medication for Anxiety and Depressive Disorders
}

\author{
By Jack M. Gorman, MD
}

When an internist diagnoses type 2 diabetes mellitus or essential hypertension in a patient, it is very likely that the initial recommendation for therapy will not include a prescription for medication. Unless the situation is severe or emergent, the physician is most likely to recommend a regimen of diet, exercise, and stress management and ask the patient to return for a reevaluation in several weeks. Only if the attempt at behavioral change is not successful will medication likely become part of the regimen. Even so, the attempt at lifestyle management will be reinforced as part of the ongoing management of the illness.

This does not mean that physicians believe that diabetes and hypertension are purely "psychological" issues. Rather, they understand that emotion and behavior have a profound impacts on somatic function, that the sensitivity of cells to insulin or the caliber of blood vessels is determined by many factors, some of which are controlled by the central nervous system.

It is ironic, then, that many psychiatrists seem to lost faith in these essential truths. Not that long ago, psychotherapy reigned as the champion of first-line interventions in psychiatry and medications were looked upon with suspicion. Today, of course, we know that psychiatric medications are safe and effective, often necessary to manage serious illnesses, and sometimes life-saving. Somehow, however, the fact that psychotherapies are also safe and effective and sometimes superior to medication management is insufficiently acknowledged.

Nowhere is this more evident than in the treatment of anxiety disorders. I am constantly asked to lecture on the treatment of anxiety and depression, but the expectation is always that I will review what is known about the pharmacologic management of these common conditions and perhaps give clinicians and patients hope by describing what is in the pipeline of the pharmaceutical companies. I am always glad to do this, because the pharmacologic management of anxiety disorders iseffective and there are fascinating molecules now in development that promise even better outcomes.

I am also astonished to realize that psychiatrists do not have the same enthusiasm to learn about psychosocial interventions. The simple fact is that for every anxiety disorderand for depression as well-there is now empirical evidence that at least one form of psychotherapy is at least as effective for most cases as medication. Furthermore, psychotherapy research has consistently shown that in some situations psychotherapy is more durable than medication management, leading to longer duration of symptom-free status.

We are delighted that Edna Foa, PhD, and Martin Franklin, PhD, along with their colleagues at the University of Pennsylvania in Philadelphia, have collected the data that make the aforementioned assertions undeniable. It is my opinion that every patient with an anxiety disorder should be told that both cognitive-behavioral psychotherapy and medication have been proven to work in rigorously controlled research studies; that there is no evidence upon which to decide which is better; that cognitive-behavioral psychotherapy has fewer adverse side effects; and that after treatment completion patient treated with psychotherapy tend to stay well longer than those who have been treated with medication. The patient should be given a choice of which modality to accept, or to have both. One model that our group and others is currently studying is to offer cognitive-behavioral therapy to all patients first, reserving medication for those who do not derive adequate benefit. It seems that we may have learned something about psychotherapy and behavior from our internal medicine colleagues.

I would also like to mention that CNS Spectrums is now receiving many very good, unsolicited research and review articles from authors around the world. This is a welcome development we wish to encourage. We are particularly interested in receiving articles from both psychiatrists and neurologists and we will work with authors for whom English is not their first language. In this way, we hope to continue to be the forum in which both disciplines learn about the best in each other's work and that brings to our attention the fine work being done all around the world.

We want to take this opportunity to alert our readers to a new feature in CNS Spectrums-letters to the editor will now be accepted. All letters will be peer-reviewed and ediled, so that acceptance of a letter is not guaranteed, but we very much want to hear from you and will make every effort to publish as many letters as possible. We will entertain letters that comment on articles already published in CNS Spectrums, interesting case reports, and new ideas. In all cases, letters should not exceed 500 words in length and should not include figures or tables. CNS 


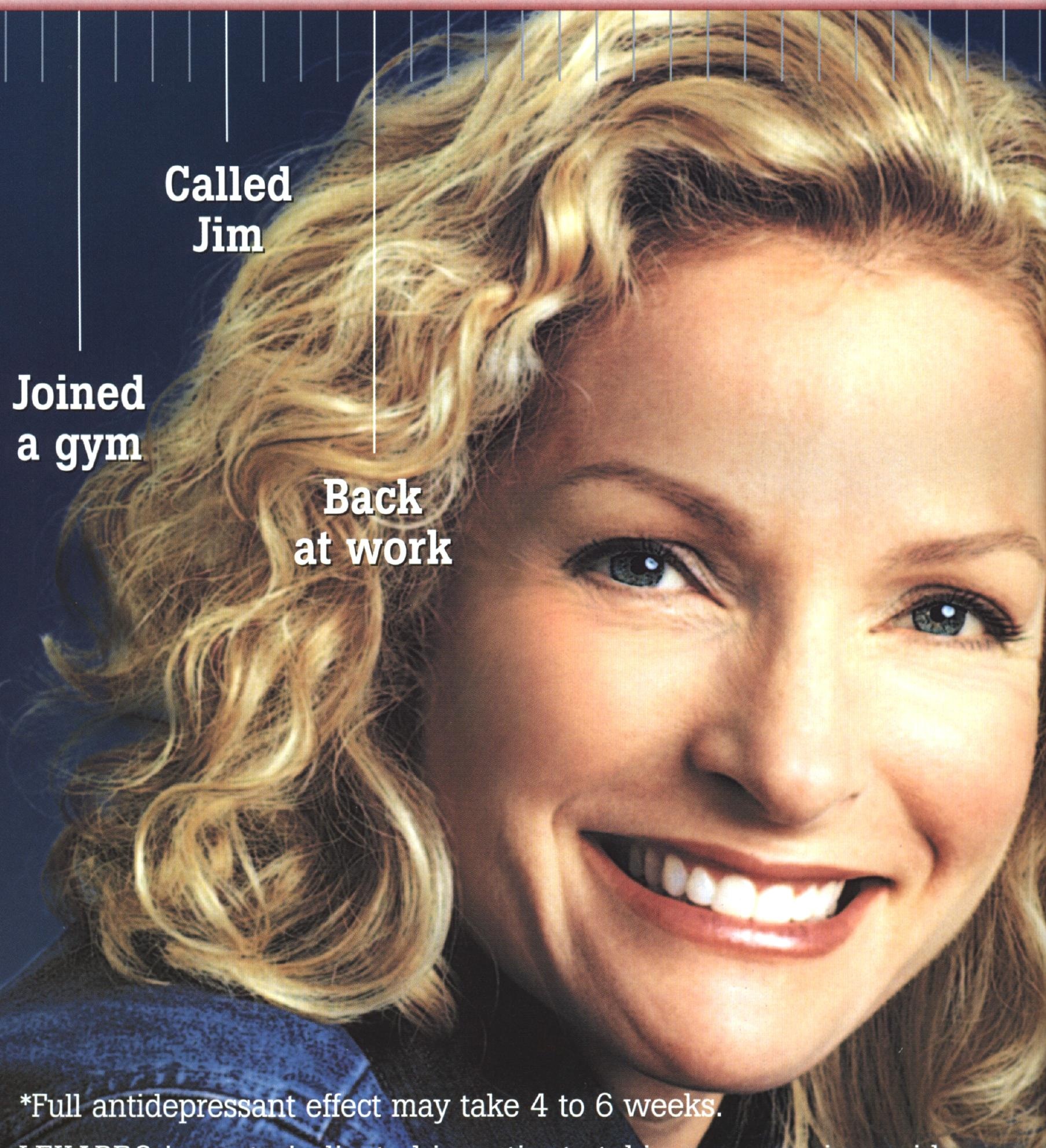

LEXAPRO is contraindicated in patients taking monoamine oxidase inhibitors (MAOIS) or in patients with a hypersensitivity to escitalopram oxalate or any of the ingredients in LEXAPRO. As with other SSRIs, caution is indicated in the coadministration of tricyclic antidepressants (TCAs) with LEXAPRO. 
How to measure

Well-tolerated therapy

in a powerful SSRI

LEXAPRO $10 \mathrm{mg} /$ day demonstrated comparable efficacy to CELEXA $40 \mathrm{mg} /$ day $^{1}$

Significantly improved depression for many patients beginning at week 1 or $2^{* 1}$

Effectively treats anxiety symptoms associated with depression ${ }^{1}$

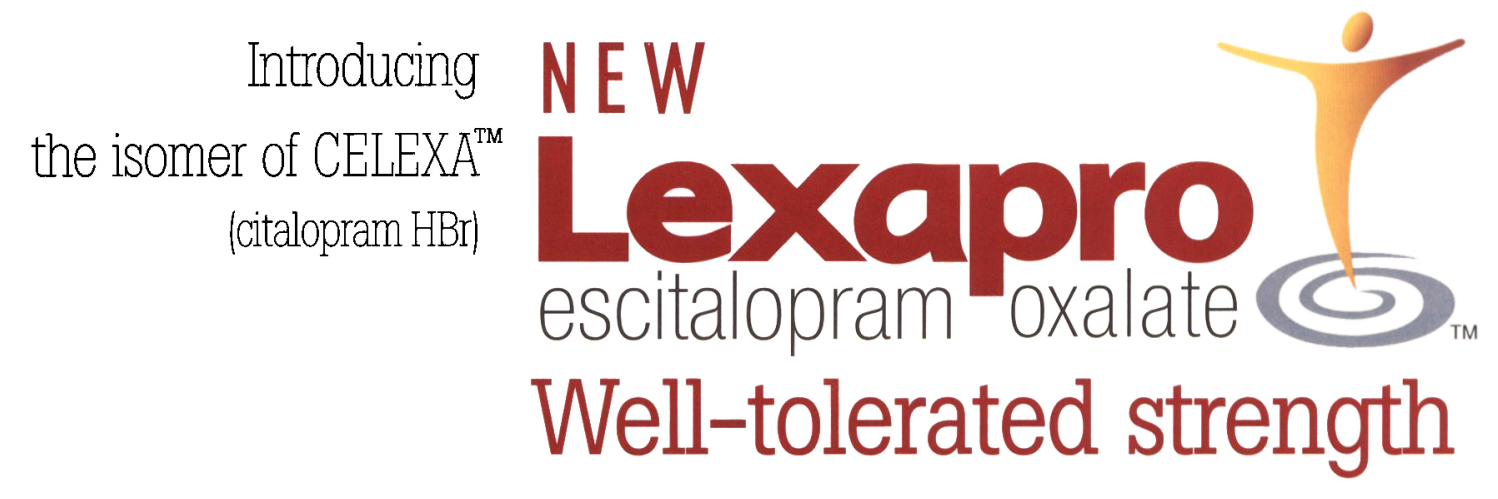




\section{How to measure}

\section{Powerful SSRI therapy}

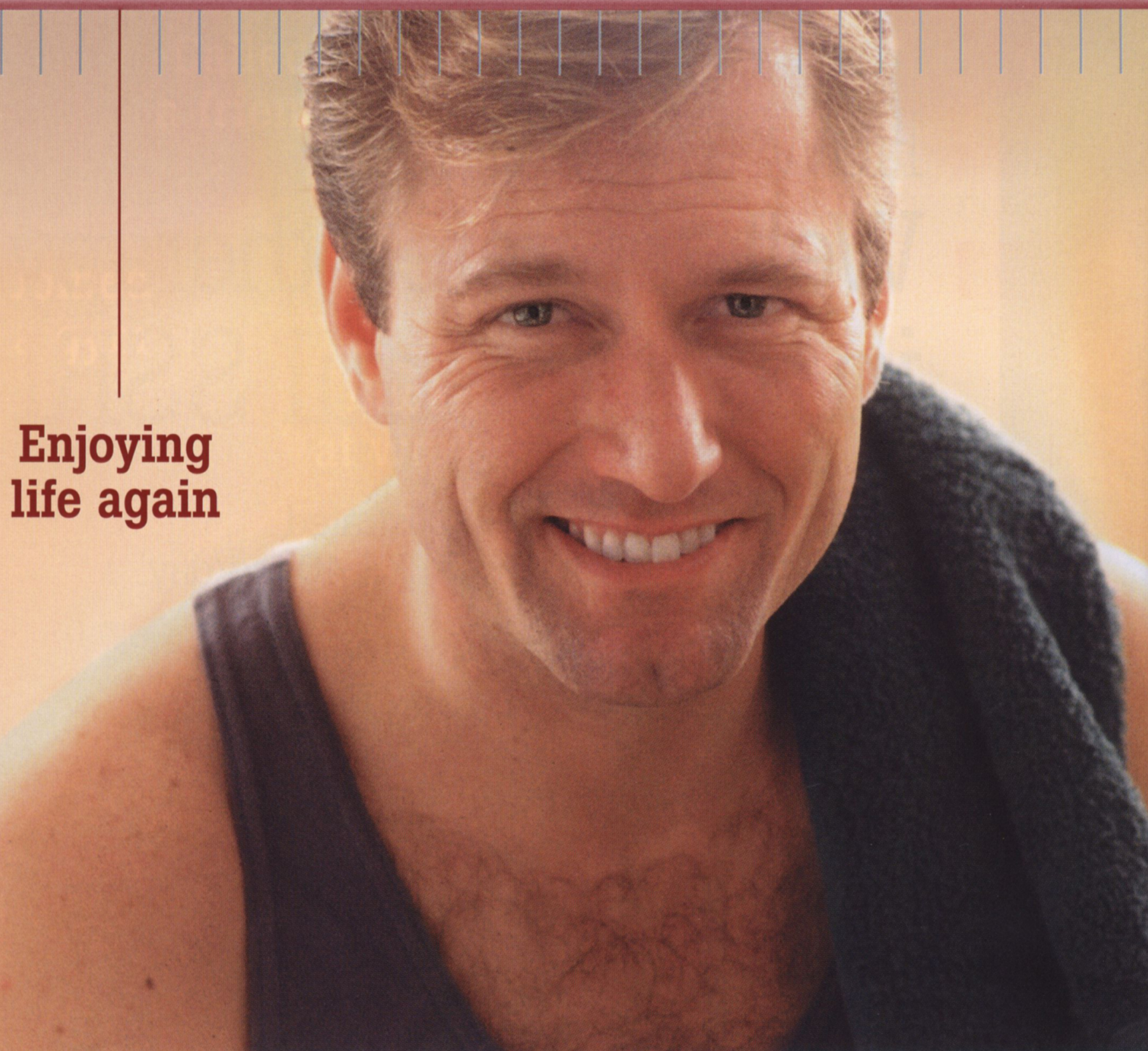

*Full antidepressant effect may take 4 to 6 weeks.

LEXAPRO is contraindicated in patients taking monoamine oxidase inhibitors (MAOIS) or in patients with a hypersensitivity to escitalopram oxalate or any of the ingredients in LEXAPRO. As with other SSRIs, caution is indicated in the coadministration of tricyclic antidepressants (TCAs) with LEXAPRO. 


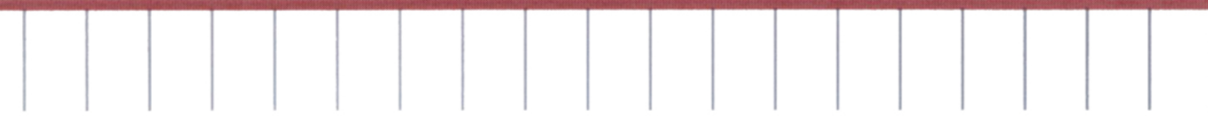

In the treatment of major depression

LEXAPRO $10 \mathrm{mg} /$ day significantly improved depression ${ }^{* 1,2}$

\section{MADRS Total Score by Visit}

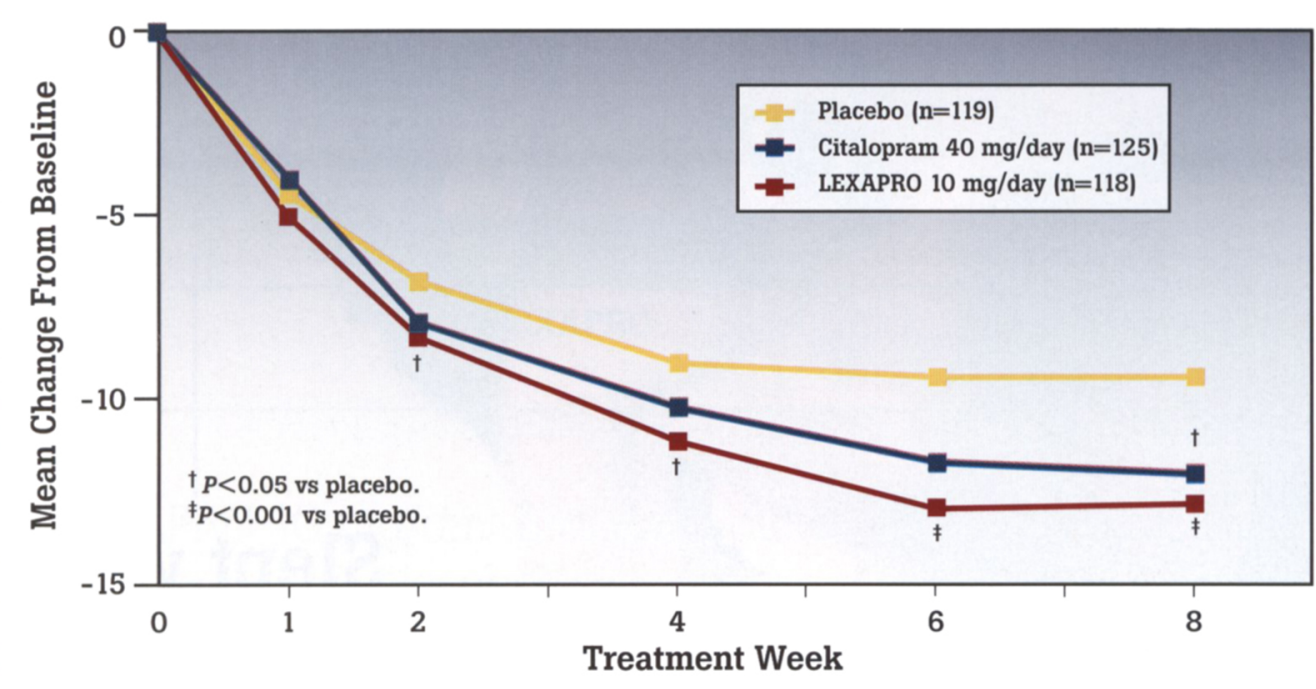

Study design: 8-week, randomized, double-blind, placebo-controlled, fixed-dose (LEXAPRO 10 or $20 \mathrm{mg} /$ day; citalopram $40 \mathrm{mg} /$ day), U.S. multicenter trial in adult patients with DSM-IV diagnosed major depression (MADRS $\geq 22$, lasting $\geq 4$ weeks). Overall mean MADRS=28.9 at baseline. I

\section{LEXAPRO $10 \mathrm{mg} /$ day demonstrated comparable efficacy to CELEXA ${ }^{\mathrm{m}}$ (citalopram $\mathrm{HBr}$ ) $40 \mathrm{mg} /$ day $^{1}$}

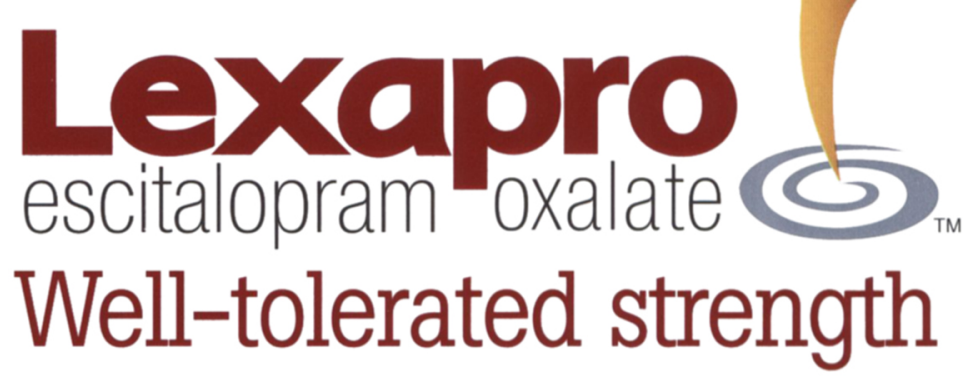




\section{How to measure Well-tolerated therapy}

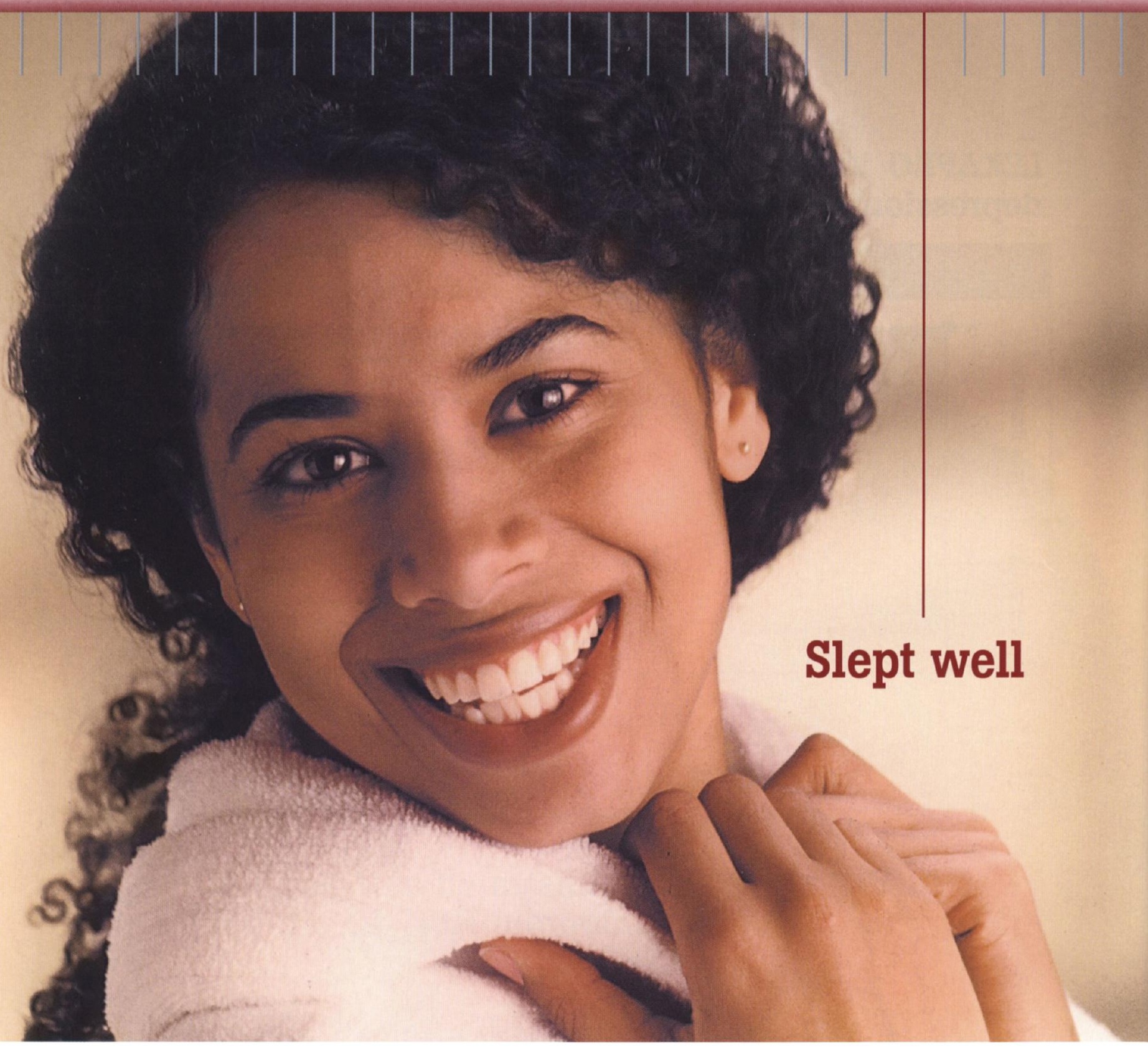

The most common adverse events reported with LEXAPRO vs placebo (approximately 5\% or greater and approximately 2X placebo) were nausea, insomnia, ejaculation disorder, somnolence, increased sweating, and fatigue.

Please see brief summaries of prescribing information for LEXAPRO and CELEXA" (citalopram HBr) at end of advertisement. 


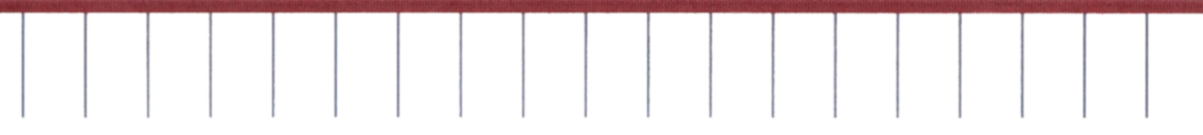

In the comprehensive safety database*

Low drop-out rates due to adverse events ${ }^{3}$

\section{Drop-Out Rates Due to Adverse Events}

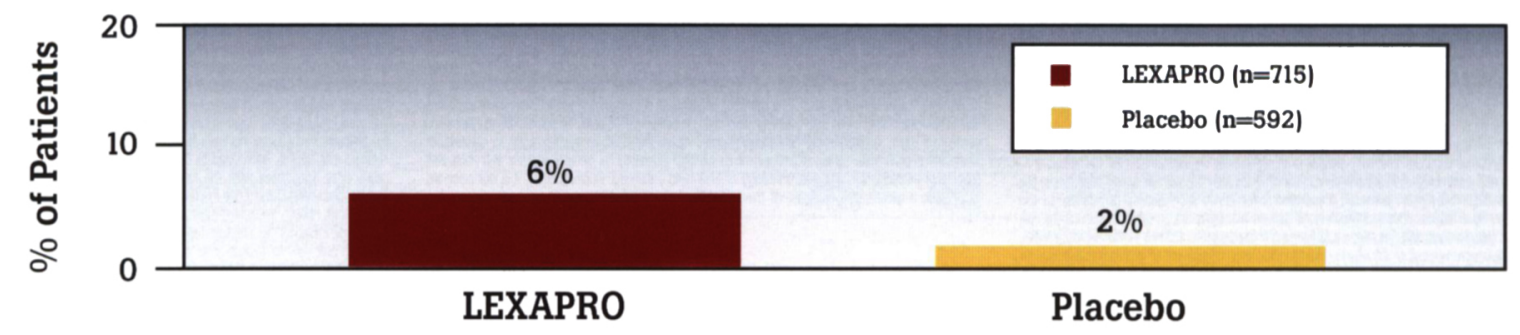

- LEXAPRO $10 \mathrm{mg} /$ day had drop-out rates due to adverse events comparable to placebo ${ }^{3}$

Favorable side-effect profile

- Only one adverse event occurred at a rate above 10\%

- LEXAPRO patients experienced no clinically important change in body weight ${ }^{3}$

Simple $10 \mathrm{mg} /$ day starting dose for all patients ${ }^{3}$

- 10 mg/day starting and maintenance dose for most patients

*Includes patients treated with 10 to $20 \mathrm{mg} /$ day.

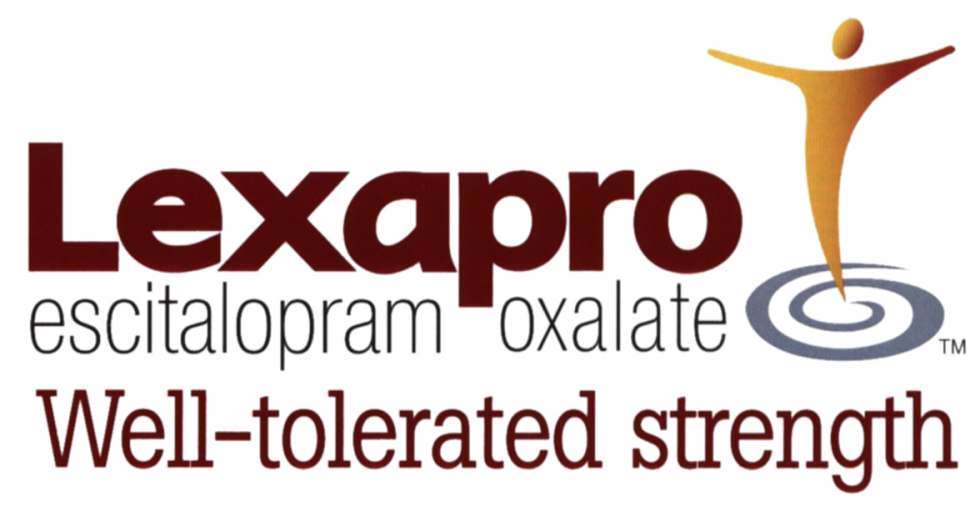


LEXAPRO ${ }^{\mathrm{TM}}$

(oscitialopram 0xalate) TABLETS
(a)

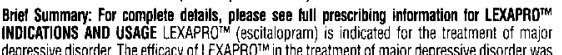

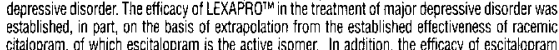
was shown in an 8-wegk controlled trial of outpatients whose diagnoses corresponded most
closenty to the DSM-VY category of major depressive cisorder (see Clinical Pharmacolooy). A major depressive episode (DSM-VI) implies a prominent and realat vely persistent (nearly every day for
at least 2 weeksi depressed or dysphoric mood that usually interteres with daily functioning, and at least 2 weeksi depressed or dysphoric mood that usually interteres w wh thaly functioning, and
includes at ieast tive of the following nine symptoms: depressed mood, loss of interest in usual

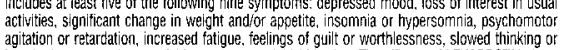
impaired concentration, a suicide attempt or suicidal ideation. The efficacy of $L E X P R 0^{\text {TW }}$ in hos-
pitalized patients with major depressive disorders has not been adequately studied. While the longer-term efficacy of LEXAPRO ${ }^{\text {Th }}$ has not been systematically eval lated, the efficasy of racemic citalopram, of which escitalopram is the active isomer, in maintaining a response following 6 to 8
weeks of acute treatment in patient's with major depressive disorder was demonstrafed in two placebo-controlled trials, if which patients werte observed for relapse for up to 24 weeks. The eff-
cacy of racemic citalopram in maintain ing a response in oatients with recurrent major depressive disorder who had responded and continued to be improveded during an initial $22-25$ weeks of traatment and were then followed for a period of up to 72 weeks vias demonstrated in a third place-
bo-contro iled trial (see Clinical Phiarmacology). Nevertheiess, the physician who elects to use

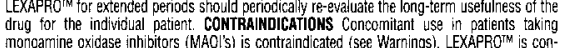
traindicated in patients with a hypersensitivity to escitalopram or citalopram or any of the inactive
ingredients in LEXAPROT. WARHINGS Polential for Interaction with Monoamine Oxidase Inhibitors in patients receiving serotonin reuptake inhibitor drugs in combination with a manoamine oxidase inhibititor (MAOl), there have been repports of serious, somatimes fatal, reactions including hyperthermia, rigidity, myoclonus, autonomic instability with possible
rapid fluctuations of vital signs, and mental status changes that include extreme agitation progressing to dellirium and coma. These reactions have also been reported in palients who have recently discontinued SSRI Ireatment and have been started on a MAOLI. Some cases pre-

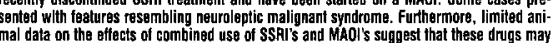
mal data on the effects of combined use of 35 Af's and MAOl's suggest that these drugs may

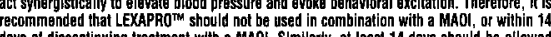

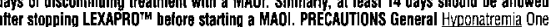
case of hyponatremia has been reported in association with LEXAPRO Th treatment Severa cases of hyponatremia or SIADH (Syndrome of inappropriate antidiuretic hormene secretion) have been
reported in association with racemic cital ooram. All patients with these events have recovered reported in association with racemic citalopram. All patients with these events have recovered
with discontinuation of escitalopram or cita opram andior medical intervention. Hyovatremia and

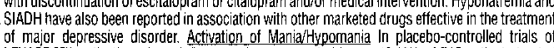
LEXAPRO
with LEXAPRi mania has aso been reported in a sinall proportion of patients with major atfective cisorcers treaed with racemic citalop ram and other marketed drugs etfective in the treatment of maior depres-
sive disorder. As with all drugus effective in the treatment of major dep ressive disorder. $L E X A P B 0^{T}$ should be used cautiously in patients with a history of mania. Seizures Although anticonvulsart
eftects of racemic citalopram have been observed in an mal studes, LEXAPRO systematically evaluated in patients with a seizure disorder. These patients were excluded
from clinical studilies duruing the producr's premarketing testing. In cliaical trials of LEXAPROT', no sezures occurred in subiects exposed to LEXAPRO'M Like other drugs effective in the treatment of major depressive disorder LEXAPRO'n should be introduced with care in
patients with a tistory of seizure disorder. Suiclice The possibility of a sulicide attempt is inherent In major depressive disorder and may persist untals significant remission occurs. Close supernt-
sion of high risk patients should accompany Initial drug therapy. As with all drugs sffective in the

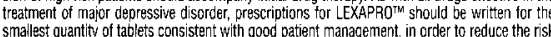
of overdose literference with coan tive and Motor Performance In situdies in normal vo: racemic citalopram in doses of $40 \mathrm{mg}$ day did not produce imparment of intellectual function of
psychomotor performance. Becausse any psychaactive dru uig may impair judderment, thinking. or

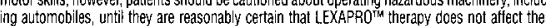

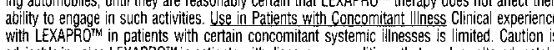

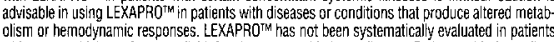
with a recent history of myocardial infarction or unstable heart disease. Patients with these diagnoses were generaly yexcluded trom clinica studes derning the product s premarketing testing. In concentrations were increased. The recommended dose of LEXAPRO ${ }^{\mathrm{T}}$ in hepatically impaired
patients is $10 \mathrm{mg}$ dday (see Dosage and Administration). Because escitalopram is extensively

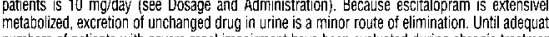

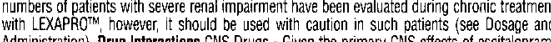
Administration), Drug Interactions CNS Drugs - Given the primary CNS effects of escita opram

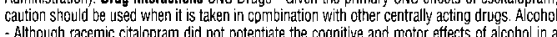
- Althought racemic citalopram did not potentiate the cognilitye and motor effects of alcohol in a
cllinical tral, as with other psychotropic medications, the use of alcohol by patients taking

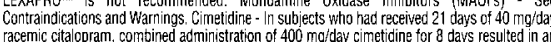
increase in citalopram AUC and $C_{\text {max }}$ of $43 \%$ and $39 \%$, respectively. The clinical sign ficance of

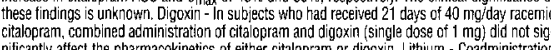

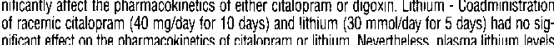
should be monitored with appropriate adjustment to the lith im dose in accordance with standarc

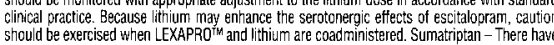

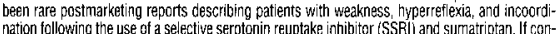

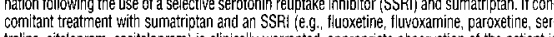
advised. Theophylline - Combined administration of racenic citalopram $140 \mathrm{cmg} / \mathrm{day}$ for 21 days

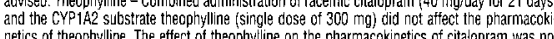

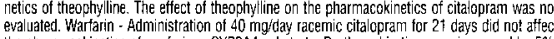

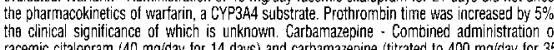
days) did not significantly atfect the rharmecokinetics of carbamazepine a CYP 394 s substrate

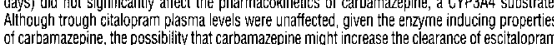

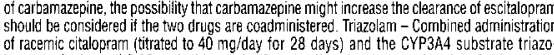

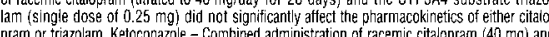

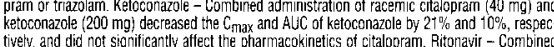
tively and did not significantly atfect the pharmacokinatics of citalopram. Ritonavir - Combined
acminisistration of a single dose of ritonavir (600 mg), both a GYP3A4 substrate and a potent

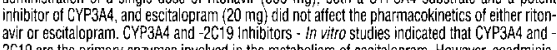
2019 are the pririmary enzyntes involved in the metabolism of escitalopram. However, coadrinis tration of escitalopram (20 mg) and ritonavir (600 mgl) a potent inhibitor of CYP3A4, did not sig-
nificantly affect the pharmacokinetics of escitalopram. Because escitalopram is metabolized by multiple enzyme systems, innibition of a single enzyme may not appreciably decrease escitalo-
pram clearance. Orugs Metabblized by Cyttochrome P450206 - in vitro studes did not reveal an

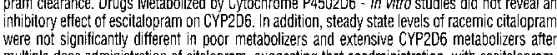
multiple-dose administration of citalopram, suggesting that coadministration, with escitalopram. of a drug that innibits CYP2DG, is unl kely to have clinically significant effects on escitalopram,

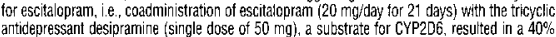
anticepressant desipramine (single dose of $50 \mathrm{mg}$ g. a substrate for CYP2D6, resulted in a $40 \%$
increase in $C_{\text {max and a }} 100 \%$ increase in AUC of desipramine. The clinical signiticance of this find-

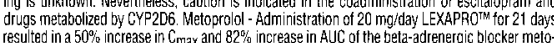

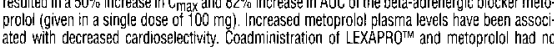

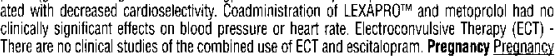

LEXAPRO $^{\text {TM }}$

Categony $C$ In a rat embyroffetal development study. ora adminisistration of escititalopram (56, 112

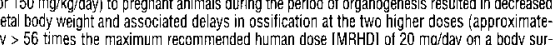

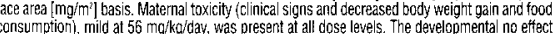
dose of 56 mokikg'day is approximately 28 times the MRHD on a molm $m^{2}$ basis. No teratogenicity emale rats were treated with escitalopram $(6,12,24$, or $48 \mathrm{mg} / \mathrm{kg}$ /day) during pregnancy and

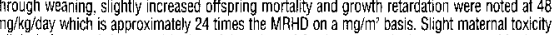
(clinical signs and decreased body weight gain and food consumption) was seen at this dose.
Slightlly increased offsoring morta ity was seen at $24 \mathrm{mg} k \mathrm{~kg} / \mathrm{day}$. The no effect dose was 12 mgikg/day which is approximately 6 times the MRHO on a mgy/min' basis. In animal reproduction

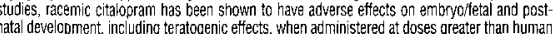
therapeutic doses. In two rat embryoffetal develicpment studies, oral administration of racemic 源

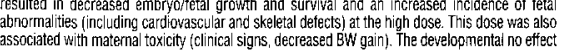

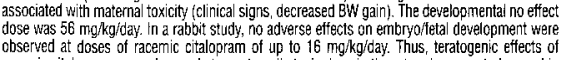
racemic citalopram were observed at a maternally toxic cose in the rat and were not observed in

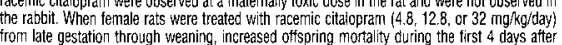
trom late gestation through weaning, increased offspring mortal tity during the first 4 days after
bitrth and persistent ofispring growth retardation were ebserved at the highest dose. The no effect dose was 12.8 mg/kg/day. Similar effeets on offspring mortality and growth were seen when
dams were treated throughout gestation and early lactation at doses $\geq 24$ mg/kg/day. A no ettect dams were treated throughout gestation and early lactation at doses 224 mg/kg/day. A no eftect
dose was not determined in that studly. There are no adequate and well-controlled studies in

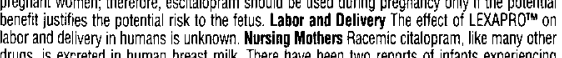
drugs. is excreted in human breast milk. There have been two reports of intants experiencing

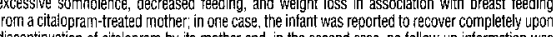
available. The decision whether to continue or discontinue ether nursing or $L E X A P P O^{T}$
therapy should take into account the risks of citalopram exposure tor the infant and the besefits
of LEXAPROTM treatrment for the mother. Pediatric Use Safety and effectiveness in pediatric patients have not been established. Geriatric Use Approximately $6 \%$ of the 715 patients receiving escitalopiarm in controlled trials of LEXAPROTM in major depressive discrder were 60 years of age
or older; elderly patients in these trials receeved daily doses of LEXAPROT between 10 and $20 \mathrm{mg}$.
The number of elderly patients in these trials was insulficient to adequately assess for possible differential efficacy and satety measures on the basis of age. Nevertheless, greater sensitivity of
some elderly ind lididuals to effects of LEXAPRO studies, escitaloprarry half-ife was increased by apporoximately $50 \%$ in elderty subjects as compared to young sebjects and $C_{\text {max }}$ was unchanged (see Clinical Pharmacology). 10 mg/day
is the recommended dose for elderty patents (see Dosage and Administration). Of 4222 patients were 75 and over. No cverall differences in safety or effectiveness were ooserved between these siubjects and younger subjects, and other reported clinical experience has not identified differences
in resconses between the elderly and younger patients, but again, greater sensitivity of some

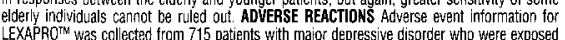
LEXAPROT was collected from 715 patients with major depressive disorder who were exposed
to escitalopramt and from 592 patients who were exposed to placebo in double-blind, placebotrials. Adverse events during exposure were obtained primarily by general inquiry and recorded by clincal investigators using terminology of their own choosing. Consequently, it is not possible
to provide a meaningtul estimate of the proportion of individuals experiencing adverse events
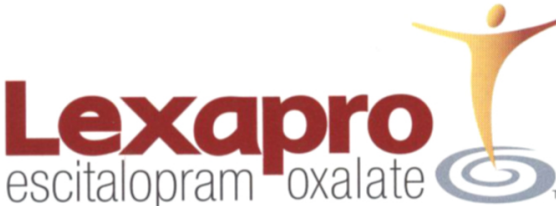

without first grouping similar types of events into a smaller number of standardized event categories. In the tables and tabulations that follow, standard World Heath Organization (WHO) terminology
has been used to classity reported adverse events. The stated frequencies of adverse events adverse event of the type listed. An event was considered ireatrment-emergent if it occurred for Associated with Discontinuation of Treatment Aincring the 715 depressed patients who Eeceived LEXAPRD'T in placebo-Controlled trials, $6 \%$ discontinued treatment due to an adverse exent, as compared to $2 \%$ of 592 patients receiving placebo. In two fixed dose studies, the rate of discon-
tinuation for adverse events in patients receiving 10 mg/day LEXAPRO'W was not significantly of discontinuation for adverse events in patents assigned to a fixed dose of $20 \mathrm{mg}$,day
LEXAPRO adverse events in patients receiving 10 mojday LEXAPRO'm ( $4 \%$ and placebo $(3 \%)$. Adverse LEXAPRO
Th Clinical Trials Tabe 1 enumerates the incidence, rounded to the nearest percent, of treatment

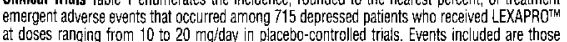

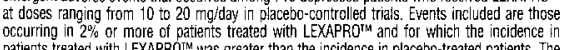
patients treated with LEXAPROTh was greater than the incidence in placebo-treated patients. The
prescriber shoudd be aware that these figures cannot be used to predict the incidenco of adverse differ from these which prevailed in the clinical trials. Similarly, the cited trequencies camnot be compared with figures obtained from other clinical investigations involving different treatments, uses, and investigators. The cited figures, however, do provice ethe prescr bing physician with
some basis for estimating the relative contribution of drug and non-drug factors to the adverse event incidence rate in the population studied. The most commonly observed adverse events in
EEXAPROT" patients (incidence of approximately $5 \%$ or greater and approximately twice the

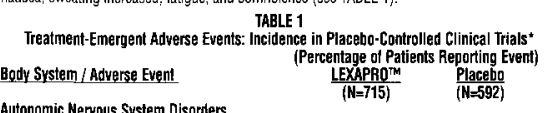

Autonomic Nervous System Disorders
Dny Mouth

Central \& Peripheral Mervous System Disorcters

$$
\begin{aligned}
& 5 \% \\
& 2 \%
\end{aligned}
$$
Diziness

Nausea
Diarrhea
Canstipntion

Indigestion
Abdominal Pain

General
Influenza-like Symptoms

Fatigue
Psychiatric Disorders
Inscmnla

Sominielence

Litidd Decreased
Respiratory System Disorders
Rhinitis

Urogusitita

Elaculation Disorder

Anrorgasmia

Events reported by at least $2 \%$ of patients treated with LEXAPRO'm are reported, except tor the following events which had an incidence on placebo $\geq$ LEXAPRO'

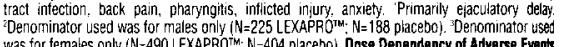

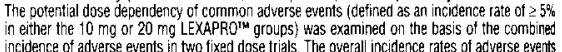
incidence of adverse events in two fixed dose trials. The overall incidence rates of adverse events

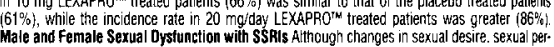
Male and Female Sexual Dysfinction with SSRis Although changes in sexual desire. Sexual per-

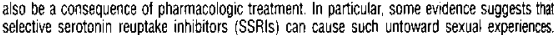
Relliable estimates of the incidence and severity of untoward experiences involving sexual desire.

\begin{tabular}{|c|c|c|}
\hline \multicolumn{3}{|c|}{$\begin{array}{l}\text { TABLL } 2 \\
\text { Incidence of Sexual Side Etfects in Placebo-Controlled Clinical Trials }\end{array}$} \\
\hline \begin{tabular}{|l|} 
Adverse Event \\
\end{tabular} & LEXAPRD ${ }^{T M}$ & Placebo \\
\hline & \multicolumn{2}{|c|}{ la Males Only } \\
\hline & $(\mathrm{N}=225)$ & $(\mathbb{N}=188)$ \\
\hline $\begin{array}{l}\text { Ejacilation Disorder } \\
\text { (primarily ejaculatory delay) }\end{array}$ & $9 \%$ & $\varsigma \%$ \\
\hline $\begin{array}{l}\text { Decreased Libido } \\
\end{array}$ & $4 \%$ & $2 \%$ \\
\hline \multirow[t]{3}{*}{ Impotence } & $3 \%$ & $<1 \%$ \\
\hline & \multicolumn{2}{|c|}{ In Females Only } \\
\hline & $(\mathrm{N}=490)$ & $(N=404)$ \\
\hline \begin{tabular}{|l} 
Decreased Linido \\
\end{tabular} & $2 \%$ & $61 \%$ \\
\hline Anorgasmia & $2 \%$ & $<1 \%$ \\
\hline
\end{tabular}
performance and satisfaction are difficult to obtain, however, in part because patients and physj.
cians may be reluctant to discuss them. Accordingly. estimates of the incidence of untoward serual experience and pertornance cited in product labeling are likely to underestimate their actual TABLF 2
Thorder in placebo controlled trials.

There are no adequately designed stucies examining sexual dystunction with escitalappram treatsexual dystunction associated with the use of SSRIS physicians should routinely inquire about
such possible side effects. Vital Sign Changes LEXAPRO'\$

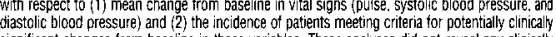
significant changes from baseline in these variables. These analyses did not reveal any clinically
important changes in vital signs associated with LEXAPRO of supine and standing vital sign measures in subjects receiving LEXAPRO's indicated that

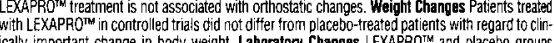
ICally important change in tody weight. Laboratory Changes LEXAPRO Th and placebo groups

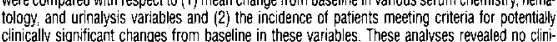

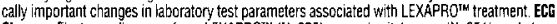
Changes Electrocardiograms trom LEXAPRO'm (N=625). racemic citatlopram ( $N=351$ ), and placebo (N=527) groups were compared with respect to (1) mean change irom baseline in various $E C G$
parameters and (2) the incidence of patients meeting criteria for potentially clinically significant

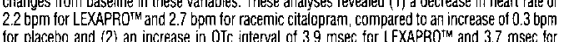

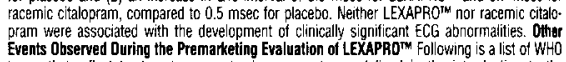

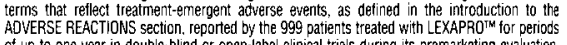
of up to one year in double-blind or open-label clinical trials duning its premarketing evaluation.
All reported events are included except those already listed in Tabe 1 , those occurring in only one patient, event terms that are 30 generala as to be uninformative. and those that are unlikely to be
drug related. It is important to emphasize that, although the events reported occurred durng treatment with LEXAPRO'th, they were not necessarily causer by it Events are further categorized by body systern and listed in order of decreasing frequency according to the following definitions:
frequent adverse events are those occurring on one or more occasions in at least 1,100 patients: patients. Cardiovascular - Frequent: palpitation, hypertension. infrequent: bradycardia tachycardia, ECG abnormal, flusting, varicose vein. Central and Peripheral Nervous Sustem Disorders -
Frequent: paresthesia, lightheaded teeling. migraine, tremor, vertigo. infrequent: shaking, dyseFrequent: paresthesia, light-headed teeling. migraine, tremor, vertigo. infrequent: shaking, dyse-
quilibrium, tics, resslless legs, carpal tunnel syndrome, twitching, faintriess, hyper reflexia, muscle contractions involuntary, muscular tone increased. Gastrointestinal Disorders - Freeguent vonit-
ing, flatulence, heartburn, tooth ache, gastroenteritis, abdominal cramp, gastroesophagea reftlux.

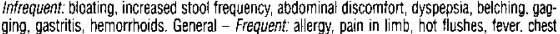

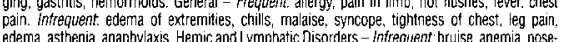
edema asthenia, anaphylaxis. Hemic and Lympnatic Disorders - Intrequent bruise, anemia, nose-
bleed, hematoma. Metabolic and Nutritional Disorders - Frequent increased weight, decreased weight. Infrequent: bilirubin increased, gout, hypercholesterolemia, hyperglycemia.
Musculoskeletal System Disorders - Frequentr arthralgia, neck'shoulder pain, muscle cramp. myalgia. Iffrequent: jaw stiffness, muscle stiffness, arthritis, muscle weakness, arthropathy, back

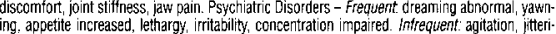
ness, apatny, panic reaction, restlessness aggravated, nervousness, forgettuness, suicide
attempt, depression aggravated, feeling uniraal, excitability, emotional lability, crying atnoimal, attempt, depression aggravated, feeling unreal, excitabillty, emotional lability, crying abnorma,
depression, anxiety attack, depersonalization, suicidal tendency, bruxism. contusion, carbohy-

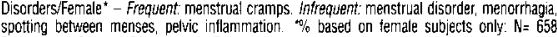
Respiratory System Disorders - Frequent bronchitis, sinus congestion, coughing, sinus headache, nasal congestion. Infrequent: asthma, breath shortness, laryngitis, pneumonia, tra-
cheitis. Skin and Appendages Disorders - Frequent: rash. Infrequent: acre, pruritus. eczema,

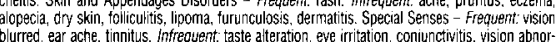

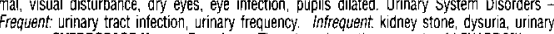
urgency. OVERDOSAGE Human Experience There have been three reports of LEXAPRO, ${ }^{\text {Th }}$ Overycose involving doses of us to $600 \mathrm{mg}$. All three patients recovered and no symptoms associated
whth the overroses weres reported. In clinical trials of racemic citalopram, there were no reports of latar citaooram overdose involving overdoses of up to $2000 \mathrm{mg}$. During the postmarketing evalcitalop ramm has been rarely reported. Postmarketing reports of drug overdoses involving citalo-
pram have included 12 fatalities, 10 in combination with other drugs andior alcohol and 2 with citalopram alone ( $3920 \mathrm{mg}$ and $2800 \mathrm{mg}$ ). as well as non-latal overdoses of up $106000 \mathrm{mg}$. Symptoms most often accompanying citalopram overdose, alone or in combination with other
drugs and 'or alsohol, included dizziness, sweating, nausea, vomiting, remor. somnolence. sinus

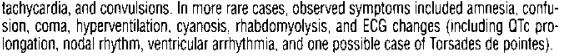

Rx Only

\section{F FOREST PHARMACEUTICALS, INC}

P 


\section{Celexa}

Tablets/Oral Solution

Ax only

Brief Summary: For complete details, please see full prescribing information for Celexa. sion. The efficacy of Celexa in the treatment of depression was established in $4-6$ week consion. The efficacy of Celexa in the treatment of depression was establisned in 4-6 week con-
tolled trials of outpatients whose diagnoses corresponded most dosely to the DSM-III and DSM-II-R category of major depressive disorder. A major depressive episode (DSM-M implies a prominent and relatively persistent (nearly every day for at least 2 weeksi depressed or dysin weight and/or appetite, insomnia or hypersomnia, psychomotor agitation or retardation, increased tatigue, feelings of guilt or worthlessness, slowed thinking or impaired concentradepressed patients has not been adequately studied. The efficacy of Celexa in maintaining an antidepressant response tor up to 24 weeks following 6 to 8 weeks of acute treabment was Celexa for extended periods should periodically re-evaluate the long-term usefulness of the monogmine oxidase inhibitors (MAO's) is contraindicated (see WABNINGS) Colera is con traindicated in patients with a hypersensitivity to citalopram or any of the inactive ingredients in Celexa. WARNINGS Potential for Imteraction with Monoamine Oxidase Inhibitors. In patidase inhibitor (MAOI), there have been reperts of serious, sornetimes fatal, reactions including hyperthermia, rigidity, myocionus, autonomic instabillty with possible rapid
fluctuations of vital signs, and mental status changes that include extreme agitation progressing to delinium and coma. These reactions have also been reported in patients Who have recently discontinued SSRI treatment and have been started on an MAOL.
Some cases presented with teatures resembling neuroleptic malignant symdrome. suggest that these drugs may act synergistically to elevate blood pressure and evoke behavicral axcitation. Therefore it is recommended that Celexa should not be used in combination with an MAOl, or wittin 14 days of discontinuing treatment with an MAOI. Similarty, at least 14 days should be allowed after stopping Celexa before starting an drome of inappropriate antidiuretic hormone secretion) have been reported in asseciation with Celexa teatment. All patients with these events have recovered with discontinuation of Celexa and/or medical intervention. Activation of Maniaj Hypornania in placebo-controlled trials of was reported in $0.2 \%$ of 1063 patients treated with celexa and in none of the 446 patients portion of patients with maior affective disorders treated with other marketed antidepresents As with all antidepressants, Celexa should be used cautiously in patients with a history of manala Seizures Athough anticonvulsant effects of citalopram have been observed in animal
studies, Celexa has not been systematically evaluated in patients with a seizure disorder. These patients were excluded from dinical studies during the product's premarketing testing. In clinical tials of Celexa, seizures occurred in $0.3 \%$ of patients treated with Celexa (a rate of one patient per 98 years of exposure) and $0.5 \%$ of patients treated with placebo (a rate of one patient per 50 years of exposure). Like other anticepressants, Ceiexa should be introduced with
care in patients with a history of seizure disorder. Suicide The possibility of a suicide attempt Is intherent in depression and may persist untilis significant remission occurs. Close supenvision witten for the smallest quantity of tablets consistent with good patient management, in order to reduce the risk of overdose. Interference With Cagnitive and Motor Performance in studives ment, thinking, or motor skills, however, patients should be cautioned about operating hazardous machinery, including automobiles, until they are reasonably certain that Celexa thera-
py does not attect their ability to engage in such activities. Use in Patients With Concomitant Illness Clinical experience with Ceilexa in patients with certain concomitant systemic illnesses ouce attered metabolism or hemodynamic responses. Celexa has not been systematically Deneraly excluded trom dinical studies during the product's pre-marketing testing. However, the electrocardiograms of 1116 patients who received Celexa in clinical trials were evaluated, and the data indicate that Celexa is not associated with the development of dinically significant ECG abnormalities. In subjects with hepatic impairment, citalopram clearance was clecreased and plasma concentrations were increased. The use of Celexa in hepatically impaired patients should be approached with caution and a lower maximum dosage is recommended. Because citalopram is extensively metabolized, excretion with severe renal impairment have been evaluated during chronic treatment with Collexa, however, it should be used with caution in such patients. Drug Interactions CNS Drugs - Given with other centrally acting drugs. Alcohol - Although citalopram did not potentiate the cognitive and motor effects of alcoho in a clinical trial, as with other psychotropic medications, the use of alcohol by depressed patients taking Celexa is not recommended. Monoamine Oxidase Inibibitors (MAOI's) - See CONTRAANDICATIONS and WARNINGS. Cimetidine - In subjects who had received 21 days of $40 \mathrm{mg} /$ day Celexa, combined administration of 400 modday cimetidine tor 8 days resutted in an increase in citalopram AUC and $C_{\text {max }}$ of $43 \%$ and $39 \%$, respec-
tively. The clinical significance of these findings is unknown. Digoxin - In subjects who had tively. The clinical significance of these findings is unknown. Digoxin - In subjects who had cose of $1 \mathrm{mg}$ i did not significantly affect the pharmacokinetics of either citalopram or digox ithium - Coadministration of Celexa 40 mg/day for 10 days) and lithium (30 mmolday for plasma lithium levels should be monitored with appropriate adiustment to the lithium cose in accordance with standard clinical practice. Becausse lithium may enhance the serotonergic effects of citalopram, caution should be exercised when Celexa and lithium are ccadministered. Theovihyline - Combined administration of Celexa (40 mg/day for 21 days) and the CYP1 2 2 substrate thecphylline (single dose of $300 \mathrm{mg}$ ) did not affect the pharrmaccokinetics of theophylline. The effect of theophylline on the pharmacokinetics of citalopram was not evalu-
ated. Sumatnotan - There have been rare postmarketing reports describing patients with ated. Sumatnotan - There have been rare postmarketing reports describing patients with
weakness, hyperreflexia and incoordination tollowing the use of a selective serotonnin reuptake weakness, hyperreflexia, and incoordination tollowing the use of a selective serotonin reuptake fluxetine, flusoxamine, paroxetine, seftraline, citalopram) is clinically warranted, appropinate days did not atfect the phammacokinetics of wartarin, a CYP3A4 substrate. Prothrombin time was increased by $5 \%$, the clinical significance of which is unknown. Cartamazepine 400 modday for 35 days) did not significantly affect the phamand carbamazepine (utrated a CYP3A4 substrate. Although trough citalopram plasma levels were unaffected, given the enzyme-inducing properties of carbamazepine, the possibility that carbamazepine might tered. Thazolam - Combined administration of Celexa (turated to $40 \mathrm{~m}$. dday for 28 days) and
the CYP3A4 substrate trazolam isingle dose of $0.25 \mathrm{mg}$ ) did not significantly affect the pharmacokinetics of either citalopram or tiazolam. Ketoconazole - Combined administration of Celexa $\left(40 \mathrm{mg}\right.$ ) and ketoconezole (200 mg) decreased the $C_{\text {max }}$ and ANC of ketoconazole by
$21 \%$ and $10 \%$, respectively, and did not significantly affect the phamacokinetics of citalopram. CYP3AA and CYP2C19 Inthibitors - in vitio studies inticated that CYP3A4 and CYP2C19 of citalopram (40 mg) and ketoconazole $(200 \mathrm{mg})$, a potent inhibitor of CYP3A4, did not sign icantly affect the pharmacokinetics of citalopiam. Because citahppram is metabolized by mutiple encyme systerns, intibition of a single enzyme may not appreciably decrease citalopram
clearance. Metoorrola - Administration of $40 \mathrm{mg} /$ day Celexa for 22 days resulted in a two-fold clearance. Metooriolol - Administration of $40 \mathrm{mg} /$ day Celexa for 22 days resulted in a two-fold
increase in the plasma levels of the beta-adrenergic blocker metoprolat. Increased metoorolo: plasma levels have been associated with decreased cardioselectivity. Coadministration of CAlexa and metoprolol had no clinically significant effects on blood pressure of heart rale
lmipramine and Other Tricyclic Antideoressants (TCA's) - in vito studies suggest that citalo. days) with the tricyclic antidepressant imipramine (single dose of $100 \mathrm{mg}$ ) mgdday for 10 CYP206 did not significantly aftect the plasma concentrations of imingming a substrate tor However, the concentration of the imipramine metabolite desipramine was increased by
approximately $50 \%$. The clinical significance of the desipramine change is unknown.
CELEXA"

Tablets/Oral Solution

CELEXA'

Tablets/Oral Solution

Nevertheless, caution is indicated in the coadministration of TCA's with Celexa troconvulsive therapy (ECT) and Celexa. Pregnancy Pregnancy Category C - There are no adequate and well-controlled studies in pregnant women; therefore, citaliopram should be used during pregnancy only if the potential beneffi justifies the potential risk to the fetus. Labor and as has been found to occur with many other drugs, citalopram is excreted in human breast milk. The decision whether to continue or discontinue either nursing or Celexa therapy shbuld treatment for the mother. Pediatric Use Safety and effectiveness in pediatic patients have not been established. Geriatric Use of 4422 patients in clinical studies of Celexa, 1357 were 60 or effectiveness were observed between these subiects and younger subjects, and other and younger patients, but greater sensitivity of some older individuals cannot be ruled out. $40 \mathrm{mg}$. In two pharmacokinetic studies, citalopram AUC was increased by $23 \%$ and $30 \%$, respectively, in elderly subjects as compared to younger subjects, and its half-ifie was ely patients. ADVERSE REACTONS The premarketing development program for Celexa ncluded citalopram exposures in patients and or normal subjects from 3 different groups of sudcies: 429 normal subjects in clinical pharmacologyy/pharmacokinetic studies; 4422 expomately 1370 patient exposure years. There were, in addition, over 19,000 exposures from mostly apen-label, European postmarketing studies. The conditions and duration of treatment with Celexa varied greatly and included (in overlapping categhries) open-label and doubletem and long-term exposure. Adverse reactions were assessed by collecting adverse events. results of physical examinations, vital signs, weights, laboratory analyses, ECGS, and results o ophthalmologic examinations. Adverse events during exposure were obtained primarily by general inquiry and recorced by dinical investigators using terminology of their own choosing.
Consequently, it is not possible to provide a meaningful estimate of the proportion of individuals experiencing adverse events without first grouping similar types of events into a smaller World Health Oranization $\mathrm{MHO}$ ) terminology has been used to classity repoted adverse events The stated trequencies of acturse events represent experienced, at least once, a treatment-emergent adverse event of the type listed. An event was considered treatment--emergent if it occurred for the first time or worsened while receiving therapy following baseline evaluation. Adverse Findings Observed in Short-Term, Placebo-Controlled Trials Adverse Events Assoclated With Discontinuation of Treatment
Among 1063 depressed patients who received Celexa at doses ranging from 10 to $80 \mathrm{mg} / \mathrm{day}$ in placebr-controlled trials of up to 6 weeks in duration, $16 \%$ discontinued trealment due to

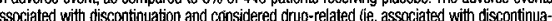

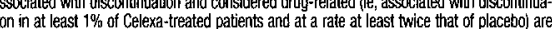
shown in TABLE 1 . It should be noted that one patient can report more than one reason for discontinuation and be counted more than once in this table.

Adverse Events Associaled With Discontinuation of Treatment in Short-Term, Percentage of Patients Discontinuing Due to Adverse Event

\begin{tabular}{|c|c|c|}
\hline Body System/Adverse Event & $\begin{array}{c}\begin{array}{c}\text { Celexa } \\
(\mathrm{N}=1063)\end{array} \\
\text { (1) }\end{array}$ & $\begin{array}{l}\text { Placebo } \\
(\mathrm{N}=446)\end{array}$ \\
\hline $\begin{array}{l}\text { General } \\
\text { Asthentia }\end{array}$ & $1 \%$ & $5 \%$ \\
\hline Gastrointestinal Disorders & & \\
\hline $\begin{array}{l}\text { Nausea } \\
\text { Dry Mouth }\end{array}$ & $\begin{array}{l}4 \% \\
1 \%\end{array}$ & $\begin{array}{c}0 \% \\
<1 \%\end{array}$ \\
\hline Vomiting & $1 \%$ & $0 \%$ \\
\hline $\begin{array}{l}\text { Central and Peripheral Nervous System Disorders } \\
\text { Dizziness }\end{array}$ & $2 \%$ & $<1 \%$ \\
\hline $\begin{array}{l}\text { Psychiatric Disorders } \\
\text { Insomnia } \\
\text { Somnolence } \\
\text { Agitation }\end{array}$ & $\begin{array}{l}3 \% \\
2 \% \\
1 \%\end{array}$ & $\begin{array}{l}1 \% \\
1 \% \\
<1 \%\end{array}$ \\
\hline
\end{tabular}

TABLE 2 enurrerates the incidence, rounded to the nearest percent, of treatment-emergent adverse events that occurred among 1063 depressed patients who received Celexa at doses
ranging from 10 to $80 \mathrm{mg} / \mathrm{day}$ in placebo-controlied trials of up to 6 weeks in duration. Events included are those occurring in $2 \%$ or more of pabents treated with Celexa and for which the incidence in patients treated with Celexa was greater than the incidence in placebo-treated dence of adverse events in the course of usual medical practice where patient characteristics and other factors differ from those which prevailed in the clinical tialls. Sirmilarly, the cited frequencies cannot be compared with figures obtained from other clinical invesugations involvprescribing physician with some basis for estimating the relative contribution of drug and nondnug factors to the adverse event incidence rate in the population studided. The only commononand at least twice the incidence in placebo patients was ejaculation disarder (primarily ejaculatory delay) in male patients (see TABLE 2).

Treatment-Emergent Atverse Events:
(id

\begin{tabular}{|c|c|c|}
\hline & Percentage 0 & Reporting Event \\
\hline Body System/Adverse Event & $\begin{array}{c}\text { Celexa } \\
(\mathrm{N}=1063)\end{array}$ & $\begin{array}{l}\text { Placebo } \\
(\mathrm{N}=446)\end{array}$ \\
\hline \multicolumn{3}{|l|}{ Autonomic Nervous System Disorders } \\
\hline Dry Mouth & $20 \%$ & $14 \%$ \\
\hline Sweating Increased & $11 \%$ & $9 \%$ \\
\hline \multicolumn{3}{|l|}{ Central \& Peripheral Nervous System Disorders } \\
\hline \multicolumn{3}{|l|}{ Gastrointestinal Disorders } \\
\hline $\begin{array}{l}\text { Nausea } \\
\text { Nations }\end{array}$ & $21 \%$ & $14 \%$ \\
\hline Diarrthea & $8 \%$ & $5 \%$ \\
\hline Dyspepsia & $5 \%$ & $4 \%$ \\
\hline Vomiting & $4 \%$ & $3 \%$ \\
\hline Abdominal Pain & $3 \%$ & $2 \%$ \\
\hline \multicolumn{3}{|l|}{ Gemeral } \\
\hline Fatigue & $5 \%$ & $3 \%$ \\
\hline & $2 \%$ & $<1 \%$ \\
\hline \multicolumn{3}{|l|}{ Musculoskeletal System Disorders } \\
\hline Arthralgia & $2 \%$ & $1 \%$ \\
\hline $\begin{array}{l}\text { Myalgia } \\
\text { Psychiatric Disorders }\end{array}$ & Psychiatric Disorders & $1 \%$ \\
\hline Somnolence & $18 \%$ & $10 \%$ \\
\hline Insomnia & $15 \%$ & $14 \%$ \\
\hline Anxiety & $4 \%$ & $3 \%$ \\
\hline Anorexia & $4 \%$ & $2 \%$ \\
\hline Agitation & $3 \%$ & $1 \%$ \\
\hline Dysmenonthea' & $3 \%$ & $2 \%$ \\
\hline Libido Decreased & $2 \%$ & $<1 \%$ \\
\hline Yawning & $2 \%$ & $<1 \%$ \\
\hline \multicolumn{3}{|l|}{ Respiratory System Disorders } \\
\hline Upper Respiratory Tract Infection & $5 \%$ & $4 \%$ \\
\hline $\begin{array}{l}\text { Rhinitis } \\
\text { Sinusitis }\end{array}$ & $5 \%$ & $3 \%$ \\
\hline Sinusitis & $3 \%$ & $<1 \%$ \\
\hline Ejaculation Disorder ${ }^{2.3}$ & $6 \%$ & Urogenital \\
\hline Impotence ${ }^{3}$ & $3 \%$ & $<1 \%$ \\
\hline
\end{tabular}

"Events reported by at least $2 \%$ of patients treated with Celexa are reported, except for the
following events which had an incidence in placebo zCelexa: headache, asthenia, dizziness, constipation, palpitation, vision abnormal, sleep disorder, nervousness, pharyngitis, micturition hol. 'Primarily ejaculatory delay. 'Denominator used was for mase celexa', $\mathrm{N}=252$ place(1) 425 Celexa; 政 dose study in depressed patients receiving placebo of Celexa $10,20,40$, and $60 \mathrm{mg}$. events: fatigue, impotence, insomnia, sweating increased, somnolence, and yawning. Mate and Female Sexual Dysfunction With SSRI's Athough changes in sexual desire, sexulal permay also be a consequence of pharmacologic treatment. In particular, some evidence suggests hat selective serotonin re-uptake inhibitors (SSFlsi) can cause such untoward sexual experiual desire, performance and satisfaction are difficult to obtain, however in port because patients and physicians may be reluctant to discuss them. Accordingly, estimates of the incidence of untoward sexual experience and performance cited in product labeling, are likely to

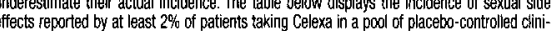
cal trials in patients with depression.
colle

\begin{tabular}{lcc}
\hline Treatment & Celexa (425 males) & Placebo (194 males) \\
\hline Abnormal Elaculation & $6.1 \%$ (males only) & $1 \%$ (males only) \\
(mostly ejaculatory delay) & & \\
Decreased Libido & $3.8 \%$ (males only) & $<1 \%$ (males only) \\
Impotence & $2.8 \%$ (males only) & $<1 \%$ (males only) \\
\hline
\end{tabular}

In female depressed patients receiving Celexa, the reported incidence of decreased libido and anorgasmia was $1.3 \%$ (n=638 females) and $1.1 \%$ (n=252 females), fespectively. There are no adequately designed studies examining sexual dysfunction with citalopram treatment.
Priapism has been reported with all SSRls. While it is difficult to know the precise risk of sexind dystunction associated with the use of SSRI's, physicians should routinely inquire atout ulal dystunction associated with the use of SSRR's, physicians should routinely inquire about
such possible side effects. Vital Sign Changes Celexa and placebo groups were compared with respect to (1) mean change from baseline in vitai signs (pulse, systolic blood pressure, and diastolic blood pressure) and (2) the incidence of patients meeting criteria for potentially dinclinically important changes in vitai signs associated with Celexa treatment. In addition, a comparison of supine and standing vital sign measures for Celexa and placebo treatments indicated that Celexa treatment is not associated with orthostatic changes. Weight Changes pared to no change for placebo patients. Laboratory Changes Celexa and piacebo groups were compared with respect to (1) mean change from baseline in various serum chemistry, hemalology, and urinalysis variables and (2) the incidence of patients meeting criteria for potentitalclinically important changes in laboratory test pararneters associated with Celexa treatment. ECG Changes Electrocardiograms from Celexa (N=802) and placebo (N=241) groups were the inciderice of patients meeting criteria for potentially clinically significant changes from was a decrease in heart rate for Celexa of $1.7 \mathrm{bm}$ compared to no change in heart rate for placebo. There were no observed differences in QT or other ECG intervals. Other Events Observed During the Premarketing Evaluation of Celexa (citalopram HBr) Following is a list of WHO terms that reflect treatment-emergent adverse events, as cefined in the introduc-
tion to the ADVERSE REACTIONS section, reported by patients treated with Celexa at multiple coses in a range of 10 to $80 \mathrm{mg} /$ /day cturing any phase of a trial within the premarketing dataor elsewhere in labeling, those events for which a drug cause was remote, those event terms which were so general as to be uninformative, and those occurring in only one patient. It is tis reported occurred during treatment with and listed in order of decreasing frequency according to the following definitions: treenuent adverse events are those occurring on one or more occasions in at least $1 / 1$ to patients; intrequent adverse events are those occurring in less than $1 / 100$ patients but at least $1 / 1000$ patients; rare events are those occurring in fewer than 1/1000 patients. Cardiovascular dia, edema (extremitites), angina pectoris, extrasystoles, cardiac tailure flushing, myocardial fartion, cerebrovascular accident, myocardial ischemia. Aare:

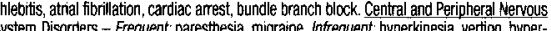
ystem Disorders - Frequent: paresthesia, migraine. Infrequent: hyperkinesia, verigo, hypoallgia, dystonia abnormal gait hypesthes, involuntary muscle contractions, hypokinesia, nebsia, ptosis, stupor. Endocrine Disorders - Rare: hypothyroidism, goiter, gynecomastia Gasuointestinal Oisorders - Frequent: sallva increased, flatulence. Infequent: gastritis, gasis. Rare colitis, gastric ulcer, chotecystitis, cholelithizsis, turdenal uicer, gastroesophage reflux, glossitis, jaundice, diverticulitis, rectal hemorrinage, hiccups. General - infrequent: het fushes, rigors, alcohol intoierance, syncope, influenza-ike symptoms. Aare: hayjever. Hemic and Lymphauce Disorders - Infequent: purpura, anemka, epistaxis, eukocytosis, leucopenta hypochromic anemia, coagulation disorder, gingival bleeding. Metabolic and Nutritiona Disorders - Frequent decreased weight, increased weight. infrequent: increased hepatic enzymes, thirst, dry eyes, increased alkaline phosphatase, abnormal glucose tolerance. Rare bilirubinemia, hypokalemia, obesity, hypoglycemia, hepatitis, dehydration. Musculoskeletal

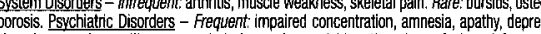
sion, increased appetite, aggravated depression, suicice attempt, confusion. infrequent increased libido, aggressive reaction, paroniria, drug dependence, depersonalization, halluci-
nation, euphoria, psychotic depression, celusion, parano:d reaction, emotional lability, panic nation, euphoria, psychotic depression, celusion, parano:d reaction, emotional lability, pantic
reaction, psychnsis. Rare: catatonic reaction, melancholia. Reproductive Disordersifemale

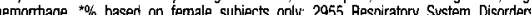
Frequent: coughing. Infrequent: bronchitis, dyspnea, pneumonia. Rare: asthma lannngits bronchospasm, pneumonitis, sputum increased. Skin and Appendages Disorders - frequent ash, pruritus. Intrequent: photosensitivity reaction, urticaria, acne, skin discoloration, eczema alopecia, dermattits, skin dry, psoriasis. Aare: hypertrichnsis, decreased sweating, melanosis, perversion. intrequent tinnitus, conjunctivitis, eye pain. Aare mydriasis, photophobia, dipiopabnormal lacrimation, cataract, taste loss. Urinary System Disorders - Frequent, polyuria edema, hematuria, oliguria, pyelonephntis, renal calculus, renal pain. Other Events observed Dhat over 30 mon-Us Postmarketing Evaluation of Celexa (citalopram been reported to be temporally associated with Celexa tratment and have not been describes elsewhere in labeling: acute renal failure, akathisia, alergic reaction, anaphylaxis, angioedema, choreaathetosis, chest pain, delinum, dyskinesia, ecchymosis, epidermal necrolysis, enthema mulotorme, gastrointestinal hemorrhage, grand mal convulsions, hemolytic aneml hepatic necosss, myoclonus, neuroleptic malgnant syndrome, nystagmes, pancreatutis, pilapism, prolactinemia, prottiombin decreased, of prolonged, ihabdomyolysis, serotonin synde pointes, and withdrawal syndrome. OVEROOSAGE Human Experience Atthoutgh there mostmarketing reports of durg ayerdoses invaling citopram have included 12 to 10 in combination with other trugs andior alcohol and 2 with citatopram alone $3920 \mathrm{mg}$ and $2800 \mathrm{mg}$ ), as weil as nonfatal overdoses of up to $6000 \mathrm{mg}$. Symptoms most often accompadizziness, sweating, nausea, voniting, tremor, somnolence, and sinus tachycardia. In more rare cases, observed symptoms included amnesia, confusion, Coma, convulsions, hypervertilation, cyanosis, rhabdomyolysis, and ECG changes fincluding QTC prolon
ventricular arntythmia, and one possible case of Torsades de pointesis

FG FOREST PHARMACEUTICALS, INC.

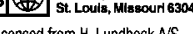

Rev. 08/02

Q2002 Forest Laboratories, In 